\title{
Evaluation of the effectiveness of piezocision-assisted flapless corticotomy in the retraction of four upper incisors: A randomized controlled clinical trial
}

\section{Ocena skuteczności bezpłatowej piezokortykotomii w retrakcji czterech górnych siekaczy - randomizowane kontrolowane badanie kliniczne}

\author{
Ghaith M.F. Al-Imam ${ }^{1, A-F}$, Mowaffak A. Ajaj ${ }^{1, B-F}$, Mohammad Y. Hajeer, ${ }^{1, D-F}$, Yaser Al-Mdalal2,C,E,F, Eyad Almashaal ${ }^{2, B, C, F}$ \\ ${ }^{1}$ Department of Orthodontics, Dental School, University of Damascus, Syria \\ ${ }^{2}$ Department of Oral and Maxillofacial Surgery, Dental School, University of Damascus, Syria \\ A - research concept and design; $\mathrm{B}$ - collection and/or assembly of data; $\mathrm{C}$ - data analysis and interpretation; \\ $D$ - writing the article; $E$ - critical revision of the article; $F$ - final approval of the article
}

Address for correspondence

Ghaith M.F. Al-Imam

E-mail: gaisimam@gmail.com

Funding sources

This project was funded by the University of Damascus

Dental School Postgraduate Research Budget

(Ref. No. 83054206781DEN).

Conflict of interest

None declared

Received on March 20, 2019

Reviewed on June 4, 2019

Accepted on July 2, 2019

Published online on December 3, 2019

Cite as

Al-Imam GMF, Ajaj MA, Hajeer MY, Al-Mdalal Y, Almashaal E. Evaluation of the effectiveness of piezocision-assisted flapless corticotomy in the retraction of four upper incisors: A randomized controlled clinical trial. Dent Med Probl. 2019;56(4):385-394. doi:10.17219/dmp/110432

DOI

$10.17219 / \mathrm{dmp} / 110432$

Copyright

๑ 2019 by Wroclaw Medical University

This is an article distributed under the terms of the

Creative Commons Attribution 3.0 Unported License (CC BY 3.0)

(https://creativecommons.org/licenses/by/3.0/)

\begin{abstract}
Background. Comprehensive orthodontic treatment may last for 20-24 months. Reducing the treatment time has become a common demand from both patients and orthodontists. Minimally invasive piezocision is one of the suggested approaches to accelerate the orthodontic tooth movement.
\end{abstract}

Objectives. The aim of this randomized controlled clinical trial was to assess the effectiveness of the flapless piezocision procedure in accelerating the retraction of upper incisors.

Material and methods. A single-blinded, parallel-group randomized controlled clinical trial was conducted at the Department of Orthodontics at the University of Damascus Dental School, Syria. The study involved 42 patients (11 males, 31 females) at the age of $16-31$ years (mean age: 19.15 years). The patients had class || division I malocclusion and were treated with fixed appliances using the two-step retraction technique. With an allocation ratio of 1:1, the participants were randomly assigned to either the experimental group ( $n=21$ ) or the control group ( $n=21$ ) using a computer-generated list of random numbers. Allocation was concealed due to the use of sequentially numbered, opaque, sealed envelopes. The primary outcomes were the rate of incisor retraction (RIR) and the time required for retraction. The outcome assessor was blinded.

Results. The data analysis included 20 patients in each group. The rate of incisor retraction significantly increased in the experimental group by 53\%, with a significant shortening of the retraction time in the experimental group by $27 \%(p<0.001)$. The rate of anchorage loss was significantly lesser in the experimental group $(p<0.001)$. Regarding the cephalometric assessment, incisor tipping was significantly greater in the control group than in the experimental group. Skeletal measurements showed insignificant changes following retraction between the 2 groups.

Conclusions. The piezocision procedure was found to be effective in accelerating the retraction of 4 upper incisors, reducing the retraction time, preserving anchorage and enhancing root torque control during retraction.

Key words: acceleration, piezocision, incisor retraction, two-step retraction

Słowa kluczowe: przyspieszenie, dekortykacja przyzębia metodą Piezocision, retrakcja siekaczy, retrakcja dwuetapowa 


\section{Introduction}

The number of patients seeking improvement in dentofacial function and esthetics has increased over the past years. ${ }^{1}$ The overall time of comprehensive orthodontic treatment with fixed appliances may amount to 24 months, ${ }^{2}$ depending on the patient's characteristics and the complexity of malocclusion. Prolonged orthodontic treatment may lead to external root resorption, hypomineralization, dental caries, periodontal disease, pain, and discomfort. ${ }^{3}$ Lengthy orthodontic treatment is considered a drawback; it is usually associated with poor patient compliance and may result in dissatisfaction. ${ }^{4}$ Therefore, the acceleration of the orthodontic tooth movement has become one of the primary concerns among orthodontists worldwide. To date, several methods have been proposed to shorten the treatment time, such as the use of low-friction self-ligating brackets (SLBs), pharmacological approaches, physical stimuli, and surgical methods. ${ }^{5}$ Surgical interventions have been found to be the most effective in enhancing the tooth movement and the most widely used, with predictable outcomes. ${ }^{6}$

These surgical interventions include conventional corticotomy, interseptal alveolar surgery, accelerated osteogenic orthodontics, dentoalveolar distraction, and periodontal distraction. ${ }^{7}$ It has been demonstrated that surgical injury to the alveolar bone can temporarily accelerate the orthodontic tooth movement by evoking the so-called 'regional acceleratory phenomenon' (RAP), which is a physiological healing response that decreases the resistance of the alveolar bone to orthodontic forces and reduces the treatment time. ${ }^{8}$

Even though the conventional corticotomy procedures have been proven to be effective in reducing the orthodontic treatment time, ${ }^{9}$ they have adverse sequelae, such as interdental bone loss, the loss of the attached gingiva, periodontal defects, and hematomas in the neck and face. These documented complications are due to the invasiveness of the traditional procedures with the need for elevating full-thickness periosteal flaps. ${ }^{10}$ Consequently, several researchers has tended to investigate less invasive surgical acceleration modalities, such as laser-assisted flapless corticotomy, piezocision, corticision, and microosteoperforations. ${ }^{6}$

Piezocision has recently evolved as a novel approach of manipulating the cortical bone with minimal damage, less discomfort and greater patient acceptance, ${ }^{11}$ and was first introduced by Vercellotti and Podesta. ${ }^{12}$ In 2009, Dibart et al. used a piezoelectric knife to achieve flapless alveolar decortication, subsequently inducing RAP with the possibility of hard or soft tissue grafting, using selective tunneling procedures. ${ }^{13,14}$ Piezocision-assisted corticotomy procedures have been investigated with several types of orthodontic tooth movement, such as resolving crowded lower anterior teeth with or without the extraction of premolars, ${ }^{15}$ the retraction of maxillary canines, ${ }^{16}$ the en-masse retraction of maxillary anterior teeth, ${ }^{17}$ and leveling and alignment in moderately crowded arches using SLBs. ${ }^{11}$

The camouflage treatment of class II malocclusion in non-growing patients includes the removal of upper first premolars with the subsequent retraction of upper front teeth. ${ }^{18}$ There are 2 main strategies to retract the anterior teeth into the retraction space - en-masse retraction and two-step retraction. The most common technique is the sequential method, in which canines are independently retracted, followed by the retraction of 4 incisors in the $2^{\text {nd }}$ stage. ${ }^{19}$

Several studies have reported speeding up canine retraction in the two-step retraction technique. ${ }^{16,20}$ In the study of Alfawal et al., canines moved 1.5-2 times faster than those retracted in the conventional way, which meant a reduction of approx. 2 months or $10 \%$ with regard to the average total orthodontic treatment time. ${ }^{16}$ Such a reduction is not clinically sufficient and it does not significantly decrease the overall treatment time. There is a need to accelerate incisor retraction in order to gain a considerable overall time reduction; however, this dimension has not yet been evaluated in the literature. ${ }^{6}$ To the best of our knowledge, there is no randomized controlled trial (RCT) assessing the efficacy of flapless piezosurgery in the retraction of 4 upper incisors in the two-step retraction technique.

Therefore, the objectives of this trial were to investigate this treatment modality in terms of rate of incisor retraction (RIR), time required for retraction and molar anchorage loss, and to assess dental and skeletal changes following the treatment.

\section{Materials and methods}

\section{Trial design and settings}

This study was a two-arm, parallel-group RCT, and there were no changes regarding its published protocol following the trial commencement. This study was conducted at the Department of Orthodontics at the University of Damascus Dental School, Syria, between September 2016 and November 2017. Ethical approval was obtained from the related Local Ethics Committee of the University of Damascus Dental School (UDDS-2938-22112015/ SRC-5927). This trial was registered in the Clinical Trials database with the identification number NCT03149016.

\section{Sample size calculation}

The sample size was calculated using Minitab $^{\circledR}$, v. 17 (Minitab Inc., State College, USA) considering that the twosample $t$-test was intended at a significance level of 0.05 and a power of $85 \%$. It was assumed that the piezocision 
intervention would decrease the overall treatment time by $40 \%$, whereas the variability of this outcome measure in a previous study was $9.27 \pm 2.55$ months ${ }^{17}$; therefore, the number of participants required in each group was 19. In order to compensate for sample attrition, 2 participants were added to each group with a total sample size of 42 patients.

\section{Participants and eligibility criteria}

Recruitment was done by screening patients who had visited the Department of Orthodontics at the University of Damascus Dental School and were seeking orthodontic treatment. Out of the 109 patients who were initially examined, 42 participants were identified to be eligible for the study. The included patients were randomly assigned to 2 equal groups with a 1:1 allocation ratio: the piezocision group (PG; $\mathrm{n}=21$ ), which received a surgical intervention, and the control group (CG; $\mathrm{n}=21)$, in which incisors were retracted in the conventional manner. All patients were chosen to meet the following inclusion criteria: class II division I malocclusion requiring the extraction of upper first premolars and the retraction of the upper anterior teeth; class II skeletal relationship $\left(4^{\circ}<\mathrm{ANB}<10^{\circ}\right)$; the clinical and radiological diagnosis of an average to vertical anterior facial height; an overjet not exceeding $10 \mathrm{~mm}$ and a normal overbite of $0-50 \%$; well-aligned maxillary incisors with mild crowding $(\leq 3.5 \mathrm{~mm})$; age of 15-26 years with a skeletal maturity stage of $\mathrm{MP}_{3 \mathrm{U}}$ or $\mathrm{R}_{U}$ depending on the hand-wrist radiograph; complete permanent dentition; no congenitally missing teeth (except for third molars); no orthodontic treatment received before; the absence of systemic disorders that could contraindicate oral surgery or affect the tooth movement; and good oral hygiene. Informed consent was obtained after a full explanation to patients and/or their parents about the purpose of the research, methods and procedures.

\section{Randomization, allocation concealment and blinding}

Simple randomization was done by one member of the academic staff not involved in this trial, using a computergenerated list of random numbers (Minitab, v. 17). The participants were randomly assigned to either PG or CG. Allocation was concealed using sequentially numbered, opaque, sealed envelopes, which were opened only after the end of the canine retraction phase. The blinding of the principal investigator and the patients was impossible, and thus blinding was only employed in the data analysis.

\section{Orthodontic treatment in both groups}

After setting up usual diagnostic records, orthodontic treatment in both groups was established using MBT preadjusted appliances with 0.022-inch slot size (American
Orthodontics, Sheboygan, USA). A soldered transpalatal arch was used to reinforce anchorage at the beginning of treatment. The teeth were leveled and aligned using the following archwire sequence: 0.014-inch NiTi (nickeltitanium); 0.016-inch NiTi; $0.016 \times 0.022$-inch NiTi; $0.017 \times 0.025$-inch NiTi; and finally $0.019 \times 0.025$-inch SS (stainless steel) (American Orthodontics). ${ }^{21}$ After the leveling phase had been finished, upper first premolars were extracted and upper canines were retracted using elastic chains until class I canine relationship was achieved. The participants were then randomized into CG or PG. Incisor retraction was initiated by soldering 5-millimeter-long power arm hooks to the basal arch distal to the brackets of lateral incisors and NiTi closed coil springs were used to deliver a continuous force of the load of $150 \mathrm{~g}$ each side to retract upper incisors. ${ }^{22}$ The force level was checked and measured every other week using a force gauge to keep it unchanged during the entire retraction stage. The incisors retraction stage was started by applying coil springs $\left(\mathrm{T}_{0}=\right.$ start of observation) and considered complete $\left(\mathrm{T}_{\mathrm{f}}=\right.$ end of observation) when one of the 2 possible events occurred: spaces lateral to incisors were closed, or a contact between upper incisors and lower incisors or the brackets on lower incisors was observed.

\section{Surgical procedure in the experimental group}

Piezosurgery was carried out at the Department of Oral and Maxillofacial Surgery at the University of Damascus Dental School, and was performed by an Oral and Maxillofacial Surgery (OMFS) Master's degree student (E.M.) under the supervision of an OMFS consultant (Y.M.). After rigorous rinsing with $0.12 \%$ chlorhexidine gluconate for $1 \mathrm{~min}$, local infiltrative anesthesia was induced in the buccal and palatal aspects of the upper anterior segment. Using a blade size 15, vertical interproximal micro-incisions were made through the periosteum between the particular teeth, $4 \mathrm{~mm}$ above the interdental papillae, and extended along the middle third of the root (Fig. 1).

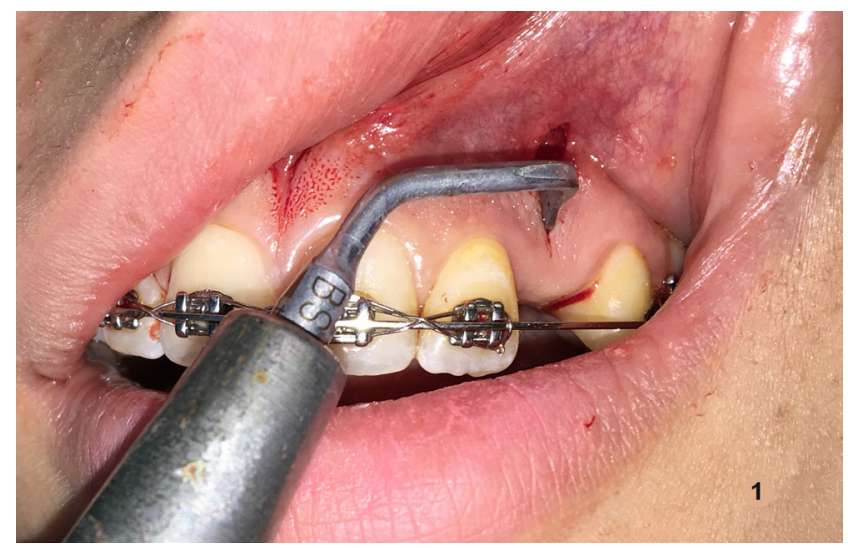

Fig. 1. Piezoelectric knife inserted to perform vertical incisions 
A piezosurgical micro-saw was used to create buccal and palatal cortical alveolar incisions to a depth of approx. $3 \mathrm{~mm}$, which was verified by a millimetric gradation on the piezosurgical knife (Fig. 2,3). The postoperative instructions given to the patients were as follows: analgesics to relieve pain (acetaminophen $500 \mathrm{mg}$ tablets thrice daily (TID) for a week); antibiotics (Augmentin 1,000 mg twice daily (BID) for a week); nonsteroidal anti-inflammatory drugs (NSAIDs) were banned, as they were expected to interfere with RAP; the application of ice packs for the next $12 \mathrm{~h}$; the avoidance of irritating food for 2-3 days after surgery; maintaining ideal oral hygiene; and rinsing with $0.12 \%$ chlorhexidine gluconate BID for a week.

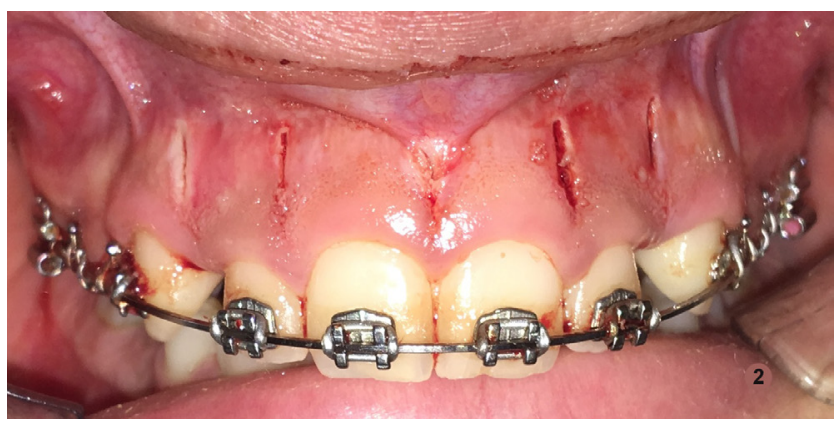

Fig. 2. Minimally invasive incisions made on the buccal aspect to induce regional acceleratory phenomenon (RAP)

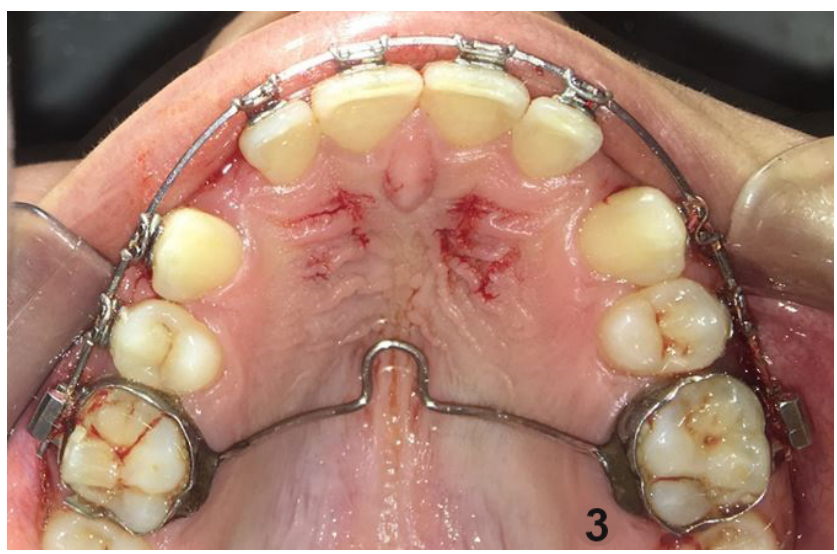

Fig. 3. Minimally invasive incisions made on the palatal aspect

\section{Primary outcome measures: Rate of incisor retraction and time required for retraction}

The primary outcome was RIR in the $3^{\text {rd }}$ week $\left(\mathrm{T}_{1}\right)$, $6^{\text {th }}$ week $\left(\mathrm{T}_{2}\right)$, $9^{\text {th }}$ week $\left(\mathrm{T}_{3}\right)$, and $12^{\text {th }}$ week $\left(\mathrm{T}_{4}\right)$, which was calculated as the distance incisors moved each week. Maxillary alginate impressions were taken for each patient at 3-week intervals starting from the onset of retraction $\left(\mathrm{T}_{0}\right)$ until the end of retraction $\left(\mathrm{T}_{4}\right)$.

Using a 0.3-millimeter graphite pencil, the following landmarks were marked on the casts by the principal researcher and re-checked by the research supervisor: the middle point of either the right or left central incisor; the medial end of the third palatal ruga as a stable landmark for assessing the anteroposterior movements of incisors and molars; and the central fossa of first molar (Fig. 4). ${ }^{23}$ The standardized digital photographs of the poured study models were taken using Nikon D80 macro twinflash 18-55-millimeter lens (Nikon, Shinagawa, Tokyo, Japan). The camera was attached to a holder specifically designed for this research project, with a model-lens distance of $30 \mathrm{~cm}$, employing perpendicular projection. The models were placed against a dark background to aid visualization. A steel millimeter ruler was inserted into each image for size correction. After digitizing the marked landmarks, linear measurements were calculated on the digital photographs using the AudaxCeph ${ }^{\circledR}$, v. 3.4.2.2710 orthodontic software (Audax d.o.o., Ljubljana, Slovenia). The displacement of the incisor segment was assessed by measuring the anteroposterior distance between the incisal edges of maxillary central incisors to the medial end of the third palatal ruga (Fig. 5). The time required for incisor retraction was recorded for both groups.

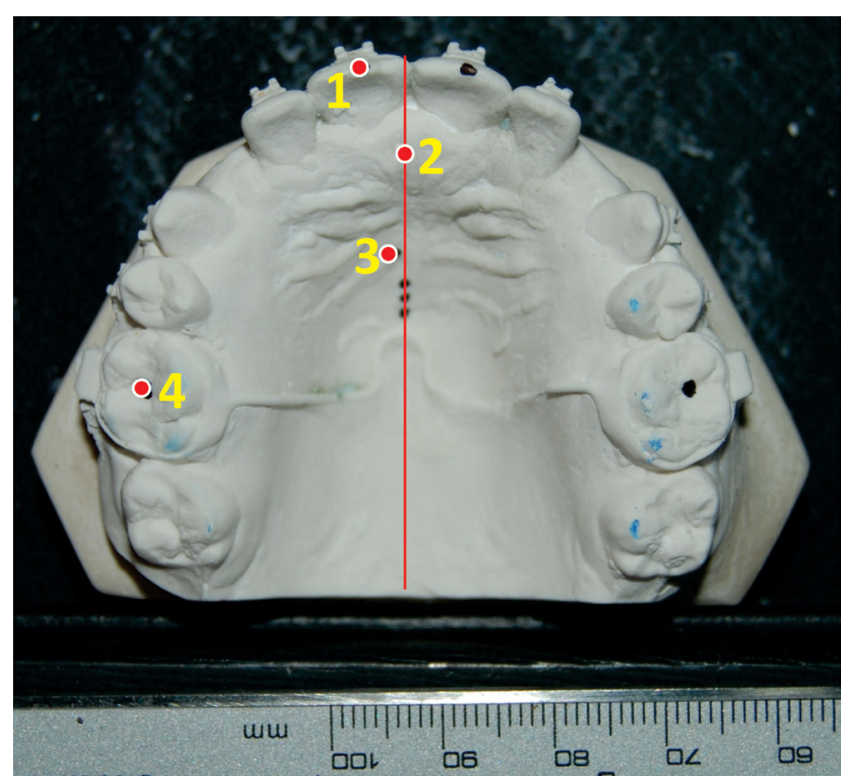

Fig. 4. Landmarks used for the plaster model analysis

1 - incisal edge of the right upper central incisor (representing all 4 incisors); 2 - mid-palatal suture line; 3 - medial end of the third palatal ruga; 4 - central fossa of the right upper first molar.

\section{Secondary outcomes: Molar anchorage loss and cephalometric variables}

\section{Molar anchorage loss}

The amount and rate of the mesial displacement of upper first molar was assessed by measuring the distance from the medial end of the third palatal ruga to the central fossa of first molar on the digital photographs of the related dental casts (Fig. 5). 


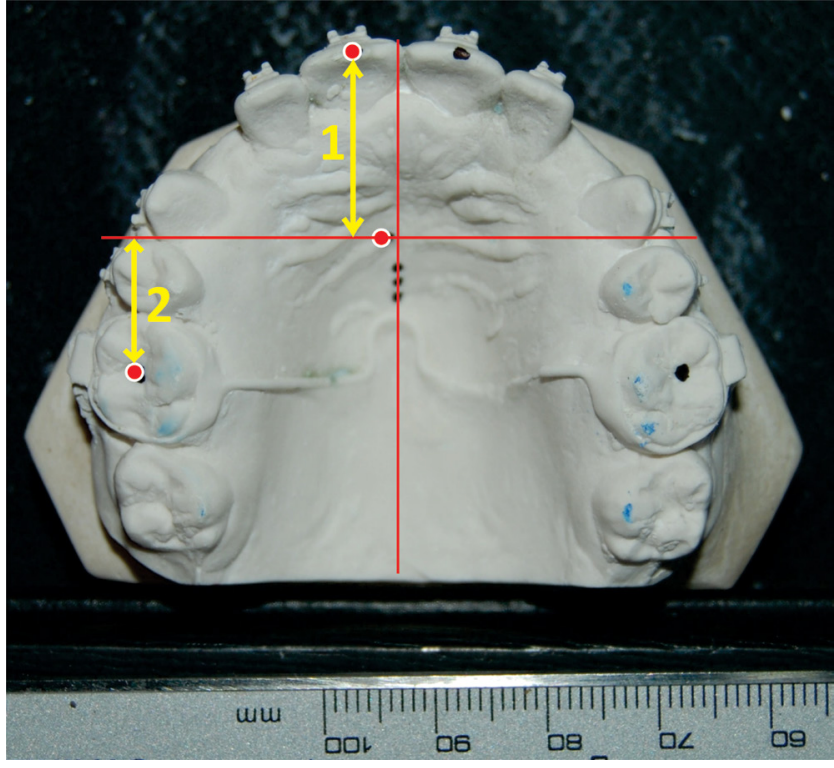

Fig. 5. Measurements made on the digitized photographs

1 - distance between the incisal edge of incisor and a perpendicular line on the mid-palatal suture line at the medial end of the third palatal ruga; 2 - distance between the central fossa of first molar and a perpendicular line on the mid-palatal suture line at the medial end of the third palatal ruga.

\section{Lateral cephalometric analysis}

Standardized lateral cephalometric radiographs were obtained at 2 assessment times: $\mathrm{T}_{0}$ (at the beginning of incisor retraction) and $\mathrm{T}_{4}$ (after the end of retraction). The rate of incisor retraction was not assessed on the lateral cephalometric

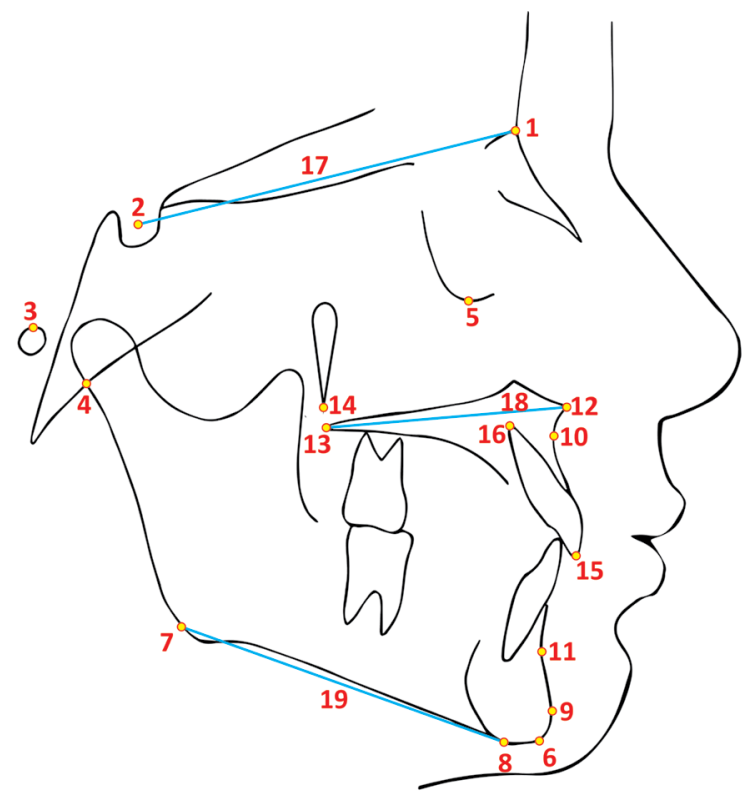

Fig. 6. Cephalometric landmarks and planes used in the present study Cephalometric landmarks: 1 - nasion (N); 2 - sella (S); 3 - porion (Po); 4 - articulare (Ar); 5 - orbitale (Or); 6 - gnathion (Gn); 7 - gonion (Go); 8 - menton (Me); 9 - pogonion (Pog); 10 - subspinale (point A); 11 supramentale (point B); 12 - anterior nasal spine (ANS); 13 - posterior nasal spine (PNS); 14 - pterygoid point (Pt point); 15 - upper incisor edge (U1E); 16 - upper incisor root apex (U1A). Cephalometric planes: 17 - anterior cranial base (SN); 18 - palatal plane (PP); 19 - mandibular plane (GoMe). radiographs for ethical reasons, i.e., to avoid exposing the patients to radiation every 3 weeks. Lateral cephalometric radiographs were taken using a Planmeca cephalometer (PM 2002 EC Proline ${ }^{\circledR}$; Planmeca, Helsinki, Finland). All subjects were positioned in the cephalostat with the path of X-rays at a right angle to the sagittal plane, the Frankfort plane parallel to the horizontal plane, the teeth in centric occlusion, and the lips relaxed. All radiographs were digitized and traced by the principal researcher. Twelve angular and 5 linear measurements were made to evaluate skeletal, dental and softtissue changes following the retraction of 4 upper incisors. The definitions of these variables are given in Table 1, and the cephalometric landmarks, planes and measurements are presented in Fig. 6 and 7. There were no outcome changes after the trial commencement.

Table 1. Definitions of angular and linear measurements used in the present study

\begin{tabular}{|c|c|}
\hline Variable & Definition (according to Al-Sibaie and Hajeer ${ }^{21}$ ) \\
\hline SNA & $\begin{array}{l}\text { the inward angle toward the cranium between the NA line } \\
\text { and the SN plane }\end{array}$ \\
\hline SNB & $\begin{array}{l}\text { the inward angle toward the cranium between the NB line } \\
\text { and the SN plane }\end{array}$ \\
\hline ANB & $\begin{array}{l}\text { the angle between the NA and NB lines obtained by } \\
\text { subtracting SNB from SNA }\end{array}$ \\
\hline SN-GoMe & $\begin{array}{l}\text { the angle between the anterior cranial base plane and the } \\
\text { mandibular plane }\end{array}$ \\
\hline MM & $\begin{array}{l}\text { the angle between the maxillary plane and the } \\
\text { mandibular plane }\end{array}$ \\
\hline $\begin{array}{l}\text { Björk } \\
\text { sum }\end{array}$ & the sum of the N-S-Ar, S-Ar-Go and Ar-Go-Me angles \\
\hline $\begin{array}{l}\text { Wits } \\
\text { appraisal }\end{array}$ & $\begin{array}{l}\text { the distance between the perpendiculars from the } \mathrm{A} \text { and } \\
\text { B points on the occlusal plane; it determines the skeletal } \\
\text { anteroposterior jaw relationship }\end{array}$ \\
\hline $\mathrm{FHI}$ & $\begin{array}{c}\text { facial height index }=\text { posterior facial height (S-Go) / } \\
\text { anterior facial height }(\mathrm{N}-\mathrm{Me}) \times 100\end{array}$ \\
\hline U1-SN & $\begin{array}{l}\text { the angle between the long axis of upper central incisor } \\
\text { and the anterior cranial base plane }\end{array}$ \\
\hline U1-SPP & $\begin{array}{l}\text { the angle between the long axis of upper central incisor } \\
\text { and the maxillary base plane }\end{array}$ \\
\hline $\begin{array}{l}\text { U1-NA } \\
\text { angle }\end{array}$ & $\begin{array}{l}\text { the angle between the long axis of upper central incisor } \\
\text { and the NA line; it defines the degree of inclination of upper } \\
\text { central incisor in relation to the maxilla and the nasion }\end{array}$ \\
\hline $\begin{array}{l}\text { U1-NA } \\
\text { distance }\end{array}$ & $\begin{array}{c}\text { the distance between the anterior point of the crown } \\
\text { of upper central incisor and the NA line; it relates the } \\
\text { sagittal position of upper central incisor to the maxilla and } \\
\text { the nasion }\end{array}$ \\
\hline U1-L1 & $\begin{array}{l}\text { the angle between the upper incisor and lower incisor } \\
\text { axes }\end{array}$ \\
\hline $\begin{array}{l}\text { Nasolabial } \\
\text { angle }\end{array}$ & $\begin{array}{l}\text { the angle formed by the lines from the columella to the } \\
\text { subnasale and from the subnasale to the upper lip }\end{array}$ \\
\hline $\begin{array}{l}\text { Mentolabial } \\
\text { angle }\end{array}$ & $\begin{array}{l}\text { the angle formed by the lines from the columella to the } \\
\text { point B and from the point B to the lower lip }\end{array}$ \\
\hline U.L.Esth & $\begin{array}{l}\text { the distance from the upper lip to the pronasale-pogonion } \\
\qquad \text { line (E-line of Ricketts) }\end{array}$ \\
\hline L.L.Esth & $\begin{array}{l}\text { the distance from the lower lip to the pronasale-pogonion } \\
\qquad \text { line (E-line of Ricketts) }\end{array}$ \\
\hline
\end{tabular}

Particular symbols are explained in the description for Fig. 6. 

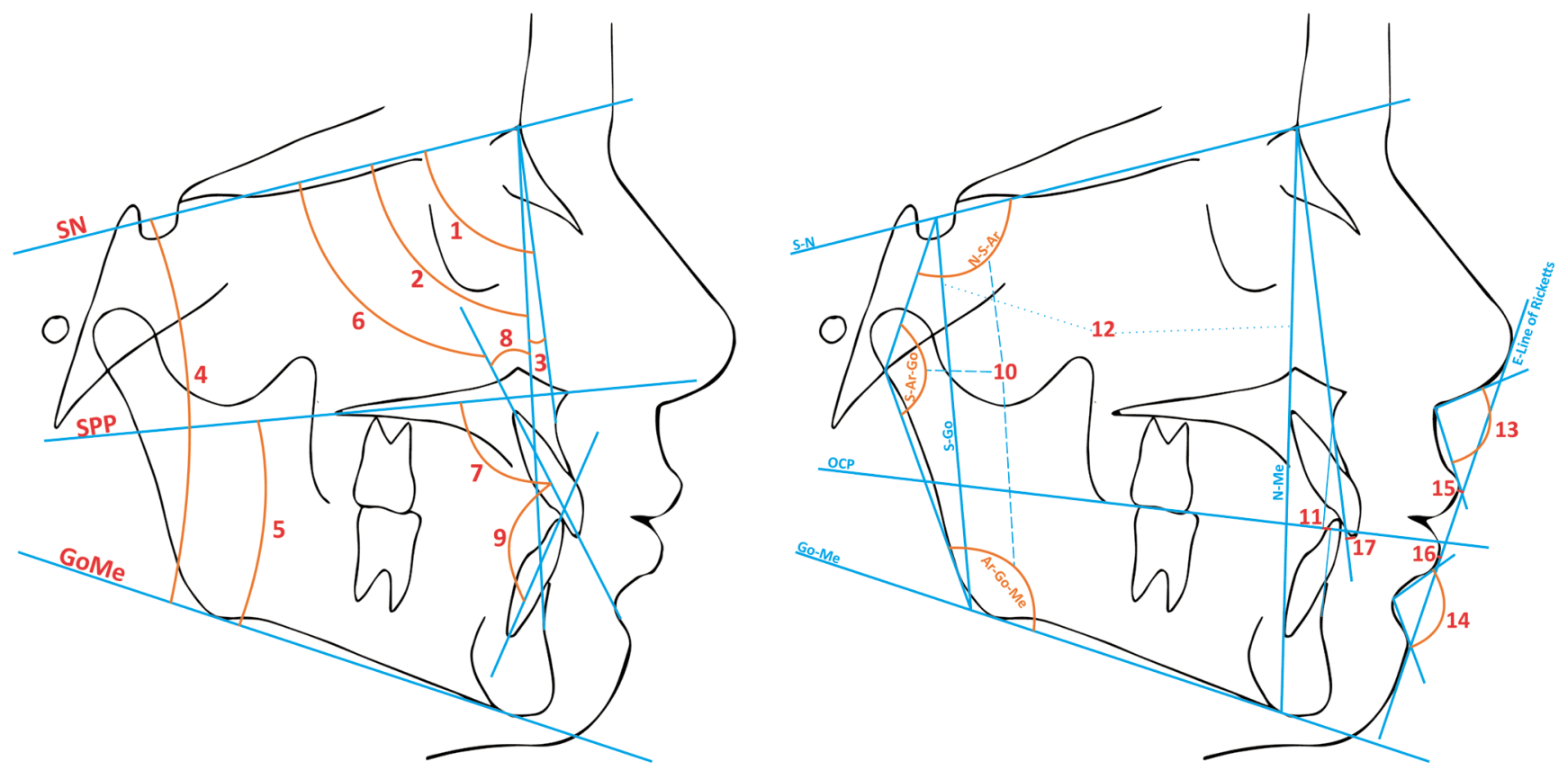

Fig. 7. Cephalometric angular and linear measurements

Cephalometric angular measurements: 1 - SNA; 2 -SNB; 3 - ANB; 4 - SN-GoMe; 5 - MM; 6 - U1-SN; 7 - U1-SPP; 8 - U1-NA angle; 9 - U1-L1;

10 - Björk sum; 11 - Wits appraisal; 12 - FHI; 13 - nasiolabial angle; 14 - mentolabial angle. Cephalometric linear measurements:

15 - upper lip-to-E-plane distance; 16 - lower lip-to-E-plane distance; 17 - U1-NA distance. OCP - occlusal plane.

\section{Statistical analysis}

The IBM SPSS Statistics for Windows, v. 20 software (IBM Corp., Armonk, USA) was used to perform all statistical analyses. Parametric tests were used, as the data distribution was deemed normal according to the Shapiro-Wilk tests. In each group, changes that occurred between every 2 time points were calculated. The two-sample $t$-test was used to detect significant differences between the 2 groups regarding the observed changes in the primary and secondary outcomes. The level of significance was set at 0.05 . The outcome data assessor was blinded to all patients' data.

\section{Error of the method}

To assess the reliability of measurements, 20 models and 20 cephalograms were randomly chosen and reanalyzed 1 month after initial assessment. The paired-sample $t$-tests were used to detect systematic errors, whereas intraclass correlation coefficients (ICCs) were used to evaluate the intra-examiner reliability (i.e., random error).

\section{Results}

\section{Patient recruitment, follow-up, entry to data analysis, and baseline sample characteristics}

Forty-two patients were enrolled in this trial and were randomly assigned to either PG or CG. One patient withdrew from CG for personal reasons and another patient was excluded from the experimental group, because she did not follow the given oral hygiene instructions thoroughly, which caused acute post-surgical inflammation at the palatal side between upper central incisors. Therefore, the data analysis stage included 40 patients who were treated between September 2016 and November 2017. The Consolidated Standards of Reporting Trials (CONSORT) flow diagram is shown in Fig. 8.

The overall sample age ranged from 16 to 31 years (mean age: $19.15 \pm 3.4$ years; $19.8 \pm 4.17$ years for the intervention group and $18.5 \pm 2.32$ years for $C G)$. The difference in mean age between the 2 groups was insignificant $(p=0.231)$. Basic sample characteristics are given in Table 2.

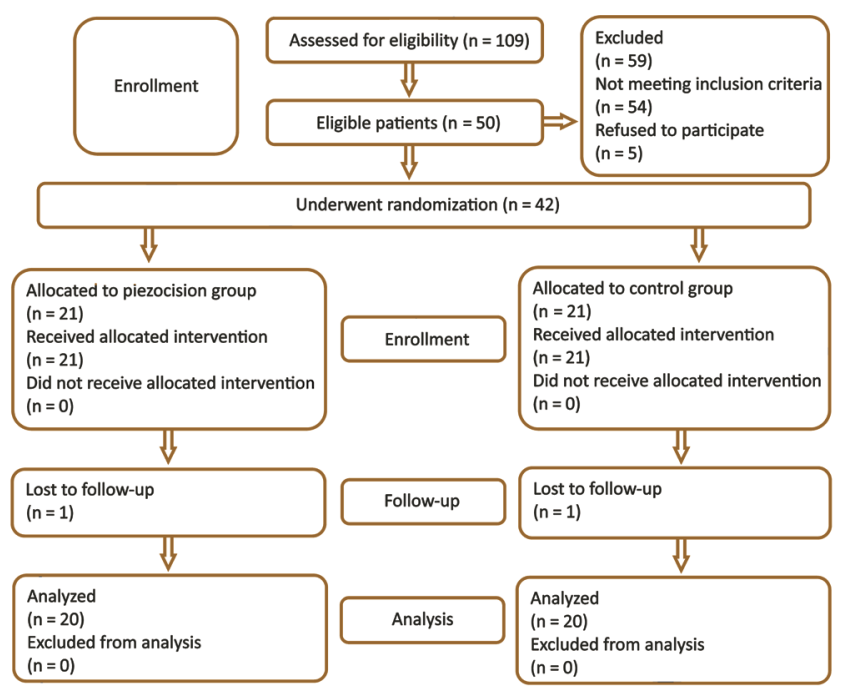

Fig. 8. Consolidated Standards of Reporting Trials (CONSORT) flow diagram of patient recruitment, inclusion and follow-up 
Table 2. Frequency of Jemt's classification scores at baseline, and at 3,6 and 9 months postoperatively

\begin{tabular}{|l|c|c|c|c|} 
Group & $\begin{array}{c}\text { Gender } \\
n(\%)\end{array}$ & p-value* & $\begin{array}{c}\text { Age [years] } \\
\text { mean } \pm \text { SD }\end{array}$ & $\begin{array}{c}\text { Max. age } \\
\text { [years] }\end{array}$ \\
\hline CG & M: $4(20)$ & $18.50 \pm 2.32$ & 31 & 16 \\
[years]
\end{tabular}

CG - control group; PG - piezocision group; M - males; F - females; SD - standard deviation; ${ }^{*}$ the $X^{2}$ test; ${ }^{* *}$ the two-sample $t$-test.

\section{Changes in the retraction distance, the rate of incisor retraction and the time required for retraction}

The mean incisor retraction distance was 6.48 $\pm 0.51 \mathrm{~mm}$ and $4.21 \pm 0.38 \mathrm{~mm}$ in the experimental and control groups, respectively. In addition, the mean difference between the 2 groups regarding the palatal displacement of incisors was significant $(p<0.001)$ (Table 3). Statistical significance was found between the 2 groups regarding RIR, which was greater in the experimental group $(0.74 \pm 0.09 \mathrm{~mm} /$ week $)$ compared to CG $(0.35 \pm 0.04 \mathrm{~mm} /$ week $)$ through the whole observation period $(p<0.001)$ (Table 4$)$. In the experimental group, RIR was increased by about $53 \%$ in comparison with the controls through the whole observation period. The mean difference in the retraction rate between the 2 groups through the entire 12-week assessment period was $0.39 \pm 0.02 \mathrm{~mm} /$ week.

Table 3. Changes in the upper incisor retraction distance (the linear distance between the medial end of the third palatal ruga and the mid-point at the incisal edge of either the right or left upper incisor) $[\mathrm{mm}]$ in the groups studied

\begin{tabular}{|c|c|c|c|c|} 
Time & $\begin{array}{c}P G(n=20) \\
\text { mean } \pm S D\end{array}$ & $\begin{array}{c}\text { CG }(n=20) \\
\text { mean } \pm S D\end{array}$ & $\begin{array}{c}\text { PG vs CG } \\
\text { mean difference } \\
(95 \% \mathrm{Cl})\end{array}$ & $p$-value \\
\hline T1-T0 & $-2.53 \pm 0.16$ & $-1.16 \pm 0.23$ & $-1.37(-1.49,-1.23)$ & $<0.001^{*}$ \\
T2-T1 & $-2.13 \pm 0.12$ & $-1.03 \pm 0.04$ & $-1.11(-1.16,-1.04)$ & $<0.001^{*}$ \\
T3-T2 & $-1.67 \pm 0.20$ & $-0.99 \pm 0.21$ & $-0.68(-0.80,-0.54)$ & $<0.001^{*}$ \\
T4-T0 & $-6.48 \pm 0.51$ & $-4.21 \pm 0.38$ & $-2.27(-2.56,-1.97)$ & $<0.001^{*}$ \\
\hline
\end{tabular}

T0 - start of observation; T1 - $3^{\text {rd }}$ week; T2 $-6^{\text {th }}$ week; T3 $-9^{\text {th }}$ week; $\mathrm{T} 4-12^{\text {th }}$ week; $\mathrm{Cl}$ - confidence interval; * statistically significant (the two-sample $t$-test).

Table 4. Changes in the upper incisor retraction rate $[\mathrm{mm} /$ week] in the groups studied

\begin{tabular}{|c|c|c|c|c|} 
Time & $\begin{array}{c}P G(n=20) \\
\text { mean } \pm S D\end{array}$ & $\begin{array}{c}C G(n=20) \\
\text { mean } \pm S D\end{array}$ & $\begin{array}{c}\text { PG vs CG } \\
\text { mean difference } \\
(95 \% \mathrm{Cl})\end{array}$ & $p$-value \\
\hline T1-T0 & $-0.84 \pm 0.05$ & $-0.39 \pm 0.07$ & $-0.46(-0.50,-0.41)$ & $<0.001^{*}$ \\
T2-T1 & $-0.71 \pm 0.04$ & $-0.34 \pm 0.01$ & $-0.37(-0.39,-0.35)$ & $<0.001^{*}$ \\
T3-T2 & $-0.56 \pm 0.06$ & $-0.33 \pm 0.07$ & $-0.23(-0.27,-0.18)$ & $<0.001^{*}$ \\
T4-T0 & $-0.74 \pm 0.09$ & $-0.35 \pm 0.04$ & $-0.39(-0.43,-0.34)$ & $<0.001^{*}$ \\
\hline
\end{tabular}

* statistically significant (the two-sample $t$-test).
The mean retraction time for the experimental group was $8.80 \pm 0.89$ weeks and $11.95 \pm 0.68$ weeks for CG. Statistical significance was observed between the 2 groups $(p<0.001)$. Therefore, the upper incisor retraction time was decreased by $27 \%$.

\section{Molar anchorage loss and cephalometric variables}

The control group exhibited a significant increase in the mean of molar anchorage loss at all observation time points compared to the experimental group $(p<0.001)$ (Table 5). Regarding the cephalometric measurements, changes that occurred in PG between $\mathrm{T}_{0}$ and $\mathrm{T}_{4}$ were compared to those observed in CG. The angles between upper central incisor and the anterior cranial base, the palatal plane, and the NA line showed a significant reduction in both groups $(p<0.001)$, and the mean reduction was significantly greater in CG compared to PG $\left(1.52^{\circ}, 1.4^{\circ}\right.$ and $1.53^{\circ}$, respectively; $\left.p<0.001\right)$ (Table 6). Furthermore, a significant increase was observed in the mean inter-incisor angle in CG compared to PG $\left(-1.11^{\circ} ; p<0.001\right)$ (Table 6). The upper and lower lips moved backward in relation to the esthetic line (E-line) of Ricketts after the end of retraction in both groups, but the movement was insignificantly greater in CG (0.41 $\mathrm{mm}$ and $0.33 \mathrm{~mm}$, respectively; $p>0.05)$ (Table 6). Regarding the skeletal assessment, the mean values of SNA, SNB and ANB insignificantly decreased in the 2 groups after the end of retraction $(p>0.05)$; however, the mean difference between the 2 groups was also insignificant $\left(-0.34^{\circ},-0.2^{\circ}\right.$ and $-0.14^{\circ}$, respectively; $\left.p>0.05\right)$ (Table 6). All the other skeletal measurements changed insignificantly following retraction $(p>0.05)$, with the differences between the 2 groups being also insignificant $(p>0.05)$ (Table 6).

Table 5. Changes in the molar anchorage loss rate $[\mathrm{mm} /$ week] in the groups studied

\begin{tabular}{|c|c|c|c|c|} 
Time & $\begin{array}{c}P G(n=20) \\
\text { mean } \pm \text { SD }\end{array}$ & $\begin{array}{c}C G(n=20) \\
\text { mean } \pm S D\end{array}$ & $\begin{array}{c}\text { PG vs CG } \\
\text { mean difference } \\
(95 \% \mathrm{Cl})\end{array}$ & $p$-value \\
\hline T1-T0 & $-0.24 \pm 0.08$ & $-0.39 \pm 0.17$ & $0.15(0.07,0.24)$ & $<0.001^{*}$ \\
T2-T1 & $-0.21 \pm 0.07$ & $-0.37 \pm 0.04$ & $0.16(0.11,0.20)$ & $<0.001^{*}$ \\
T3-T2 & $-0.17 \pm 0.03$ & $-0.39 \pm 0.05$ & $0.22(0.19,0.25)$ & $<0.001^{*}$ \\
T4-T0 & $-0.22 \pm 0.04$ & $-0.39 \pm 0.04$ & $0.17(0.40,0.20)$ & $<0.001^{*}$ \\
\hline
\end{tabular}

* statistically significant (the two-sample $t$-test). 
Table 6. Comparison of the groups studied in terms of the cephalometric measurements

\begin{tabular}{|c|c|c|c|c|}
\hline Variable & $\begin{array}{c}P G(n=20) \\
\text { mean } \pm S D\end{array}$ & $\begin{array}{l}C G(n=20) \\
\text { mean } \pm S D\end{array}$ & $\begin{array}{c}\text { PG vs CG } \\
\text { mean difference } \\
(95 \% \mathrm{Cl})\end{array}$ & $p$-value \\
\hline $\mathrm{SNA}\left[^{\circ}\right]$ & $-0.56 \pm 0.58$ & $-0.22 \pm 0.62$ & $-0.34(-0.73,0.04)$ & $>0.05$ \\
\hline SNB $\left[^{\circ}\right]$ & $-0.27 \pm 0.50$ & $-0.06 \pm 0.60$ & $-0.20(-0.55,0.15)$ & $>0.05$ \\
\hline ANB $\left[^{\circ}\right]$ & $-0.29 \pm 0.29$ & $-0.15 \pm 0.21$ & $-0.14(-0.31,0.03)$ & $>0.05$ \\
\hline SN-GoMe [] & $-0.47 \pm 0.65$ & $-0.67 \pm 0.41$ & $0.20(-0.16,0.55)$ & $>0.05$ \\
\hline $\mathrm{MM}\left[^{\circ}\right]$ & $-0.39 \pm 1.00$ & $-0.34 \pm 1.13$ & $-0.05(-0.73,0.64)$ & $>0.05$ \\
\hline Björk sum [ํ] & $-0.67 \pm 0.83$ & $-0.63 \pm 0.97$ & $-0.05(-0.63,0.53)$ & $>0.05$ \\
\hline $\begin{array}{l}\text { Wits appraisal } \\
\text { [mm] }\end{array}$ & $-0.24 \pm 0.24$ & $-0.45 \pm 0.39$ & $0.21(0.00,0.42)$ & $>0.05$ \\
\hline $\mathrm{FHI}[\mathrm{mm}]$ & $-0.77 \pm 0.51$ & $-0.82 \pm 0.63$ & $0.05(-0.32,0.42)$ & $>0.05$ \\
\hline U1-SN [ํ] & $-7.88 \pm 2.28$ & $-9.40 \pm 1.39$ & $1.52(0.31,2.73)$ & $<0.001^{*}$ \\
\hline U1-SPP $\left[^{\circ}\right]$ & $-8.08 \pm 2.01$ & $-9.47 \pm 1.42$ & $1.40(0.28,2.51)$ & $<0.001^{*}$ \\
\hline $\begin{array}{l}\text { U1-NA } \\
\text { angle }\left[^{\circ}\right]\end{array}$ & $-6.80 \pm 2.38$ & $-8.33 \pm 3.85$ & $1.53(0.13,2.93)$ & $<0.001^{*}$ \\
\hline $\begin{array}{l}\text { U1-NA } \\
\text { distance [mm] }\end{array}$ & $-2.62 \pm 1.19$ & $-3.23 \pm 1.55$ & $0.62(-0.27,1.51)$ & $>0.05$ \\
\hline U1-L1 [] & $4.86 \pm 1.40$ & $5.96 \pm 1.78$ & $-1.11(-2.14,-0.08)$ & $<0.001^{*}$ \\
\hline $\begin{array}{l}\text { Nasolabial } \\
\text { angle }\left[^{\circ}\right]\end{array}$ & $5.91 \pm 2.81$ & $5.98 \pm 3.41$ & $-0.06(-2.07,1.94)$ & $>0.05$ \\
\hline $\begin{array}{l}\text { Mentolabial } \\
\text { angle }\left[^{\circ}\right]\end{array}$ & $8.06 \pm 6.60$ & $6.69 \pm 4.51$ & $1.37(-2.25,4.99)$ & $>0.05$ \\
\hline U.L.Esth [mm] & $-1.52 \pm 0.40$ & $-1.93 \pm 0.92$ & $0.41(-0.06,0.87)$ & $>0.05$ \\
\hline L.L.Esth $[\mathrm{mm}]$ & $-1.08 \pm 0.46$ & $-1.41 \pm 0.59$ & $0.33(-0.01,0.67)$ & $>0.05$ \\
\hline
\end{tabular}

* statistically significant (the two-sample $t$-test). The CG values were subtracted from the PG values.

\section{Discussion}

This single-blinded, two-arm, parallel-group randomized controlled clinical trial was designed to investigate the efficacy of the piezocision technique in the retraction of 4 upper incisors using sliding mechanics. There was no significant difference between the 2 groups at $\mathrm{T}_{0}$ in the distance between the incisal edges to the third palatal ruga, which assured the similarity of the compared groups.

In order to retract incisors, $\mathrm{NiTi}$ closed coil springs were used, as they exert force at a constant level and maintain good oral hygiene. The 5-millimeter-long hooks enabled the adjustment of the force level so that the line of action of force could pass as much as possible through the center of resistance of upper central incisors, enabling the bodily movement of incisors during retraction. It has been demonstrated that the center of resistance during the retraction of 4 upper incisors is located within the midsagittal plane, approx. $6 \mathrm{~mm}$ apical and $4 \mathrm{~mm}$ posterior to the line perpendicular to the occlusal plane from the labial alveolar crest of central incisor, and $5 \mathrm{~mm}$ apical to the bracket position..$^{24}$

The results of the current trial cannot be compared with those of other published papers, since this is the first RCT evaluating the piezocision-assisted retraction of 4 upper incisors with sliding mechanics. In the present study, the piezocision procedure was found to be effective and shortened the overall time required for incisor retraction by $27 \%$ (approx. 4 weeks). Therefore, a 4-week time reduction in a procedure that usually takes $12-16$ weeks can be considered clinically important. It has been emphasized that orthodontists would embrace a new adjunctive intervention to accelerate the orthodontic tooth movement if it shortened the treatment time by $20-40 \% .{ }^{25}$ Accordingly, piezocision-assisted upper incisor retraction may be an acceptable treatment modality to reduce the treatment time. Even though incisor retraction is part of overall extraction treatment, flapless piezocision can be redone to accelerate several stages of the treatment, ${ }^{26}$ i.e., the canine retraction phase and the incisor retraction phase. In the current study, we looked at a specific period of the treatment sequence. We are totally aware that we evaluated a small portion of the whole scenario, but when we add the time reduction obtained in the current work with other time reductions revealed by other researchers in other portions of the treatment sequence, an overall reduction in the treatment time becomes apparent.

We found that upper incisors in the experimental group moved backward to a greater extent than those in CG (6.48 $\pm 0.51 \mathrm{~mm}$ and $4.21 \pm 0.38 \mathrm{~mm}$ in PG and CG, respectively). This can be explained by the effect of piezocision surgery on reducing dense cortical bone resistance to the orthodontic tooth movement. The rate of upper incisor retraction in the experimental group during the first 3 weeks was approx. twice as big as that observed in CG $(0.84 \pm 0.05 \mathrm{~mm} /$ week and $0.39 \pm 0.07 \mathrm{~mm} /$ week in PG and CG, respectively). These results indicate a $53 \%$ higher retraction rate. This mean rate slightly decreased to $52 \%$ and $41 \%$ between the $3^{\text {rd }}$ and the $6^{\text {th }}$ week and between the $6^{\text {th }}$ and the $9^{\text {th }}$ week, respectively. A recently published report on RCT conducted by Tunçer et al. addressed piezocision-assisted en-masse retraction. ${ }^{17}$ The researchers reported an insignificantly higher rate of retraction in the experimental group at all time points except for day 90 (i.e., the $13^{\text {th }}$ week), whereas the current trial showed a superior rate of retraction in the experimental group compared to the controls extending until the $9^{\text {th }}$ week following surgery. Additionally, Tunçer et al. did not find any significant difference in the retraction speed between the 2 groups. ${ }^{17}$ This can be attributed to the insufficient amount of bone injury that was performed in their study, since they restricted their incisions to the labial cortex of the alveolus with no intervention on the palatal side. In the current study, the palatal intervention was undertaken to initiate RAP at the sites where the teeth were moving forward. ${ }^{27}$ Apparently, it is not logical to compare the en-masse retraction of the 6 anterior teeth with incisor retraction, as there are differences between the 2 treatment modalities, such as longer treatment time, higher anchorage requirements and a greater root surface area in the enmasse retraction technique. Besides, in the 2 techniques, different orthodontic biomechanics is employed. 
Despite the conclusion of Tunçer et al. that piezocision was ineffective in accelerating the en-masse retraction of the maxillary anterior teeth, ${ }^{17} 2$ other publications reported opposite findings. Bhattacharya et al. used the so-called 'accelerated osteogenic orthodontics' (AOO) to enhance the en-masse retraction of the upper anterior teeth and found that the treatment time in the experimental group was approx. $45 \%$ shorter than that in the control group, ${ }^{28}$ whereas Sakthi et al. assessed the corticotomyassisted en-masse retraction of the anterior teeth in the treatment of bimaxillary protrusion and showed that the rate of space closure was significantly higher in the corticotomy group. ${ }^{29}$ However, these 2 aforementioned studies are not comparable to our study due to the different number of teeth involved in the retraction technique and the invasiveness of the procedures undertaken in these 2 studies, i.e., the traditional elevation of full-thickness labial and lingual periosteal flaps.

The piezocision-assisted two-step retraction technique is expected to play an important role in our daily practice and might be superior to piezocision-assisted enmasse retraction, since it has been shown that a significant improvement in the speed of canine retraction can be achieved by minimally invasive methods, ${ }^{6,16}$ and the results of the current trial show that also the time of incisor retraction can be significantly shortened when using these methods.

Regarding molar anchorage loss, CG exhibited a higher rate of molar mesial movement by about $44 \%$ compared to the experimental group in the whole observation period. It has been postulated that corticotomy procedures have the advantage of enhancing anchorage by providing the differential movement of the anchoring and nonanchoring teeth, i.e., the teeth located in the corticotomized regions tend to move more readily than those in the non-corticotomized regions. ${ }^{8}$ Thus, piezocision seems to facilitate the tooth movement with lighter orthodontic forces and, therefore, reduces the load applied to the posterior anchoring teeth. These results are in agreement with previous investigations which addressed the acceleration of en-masse retraction. ${ }^{17,29}$

All skeletal measurements showed insignificant changes following the retraction of 4 upper incisors. It has been concluded that there are no significant differences in the changes in the skeletal measurements when comparing the accelerated to non-accelerated retraction of the maxillary anterior teeth. ${ }^{30}$ However, in this trial, the significant post-retraction changes between CG and PG in the mean values of U1-SN, U1-SPP, U1-NA, and U1-L1 indicated that the type of movement of incisors after the end of retraction had a greater translational component in the experimental group, whereas in the controls, the type of movement was controlled tipping. This might be explained by the induced RAP effect, which may have facilitated the expression of the root torque during retraction.
There are some limitations of this study. A high percentage of female patients $(77.5 \%)$ constituted this sample; therefore, inter-gender differences could not be investigated. Patient-centered outcomes, quality of life and the levels of acceptance were not evaluated in this trial. There was no post-surgical follow-up to investigate the effects of piezosurgical incisions on the labial gingivae (i.e., residual scars) as well as on the periodontal status. The blinding of the patients and the researcher was impossible; however, this could not be a source of bias, since no patient-centered self-assessed outcomes, such as the feeling of pain, discomfort or swelling, were evaluated.

One unexpected post-surgical complication in the experimental group was noticed in 1 patient who was excluded from the trial. One week after the piezocision procedure, an acute inflammatory response developed between central incisors in the midline at the palatal side. Appropriate care was provided for this patient, but a 2-millimeter recession of the interdental papilla in the midline was documented and retraction was resumed after 2 months. In the literature, there are no previous reports on periodontal complications following flapless corticotomy in the retraction of the anterior teeth.

\section{Conclusions}

Piezocision proved to be effective in accelerating the retraction of 4 upper incisors, with the rate of retraction higher by $53 \%$ in PG compared to CG in the whole observation period. The incisor retraction period was shortened by $27 \%$ compared to the controls. The results of this study also showed a significant change in the type of incisor retraction movement, which was predominantly translational movement in PG and controlled tipping movement in CG. The rate of molar anchorage loss was significantly higher in CG compared to the corticotomy group.

\section{ORCID iDs}

Ghaith M.F. Al-Imam (D) https://orcid.org/0000-0002-8541-6202 Mowaffak A. Ajaj (D) https://orcid.org/0000-0002-8602-6986 Mohammad Y. Hajeer (D) https://orcid.org/0000-0003-0640-1297 Yaser Al-Mdalal (D) https://orcid.org/0000-0002-8578-6289 Eyad Almashaal (D) https://orcid.org/0000-0003-4745-7895

\section{References}

1. Mathews DP, Kokich VG. Managing treatment for the orthodontic patient with periodontal problems. Semin Orthod. 1997;3(1):21-38.

2. Tsichlaki A, Chin SY, Pandis N, Fleming PS. How long does treatment with fixed orthodontic appliances last? A systematic review. Am J Orthod Dentofacial Orthop. 2016;149(3):308-318.

3. Talic NF. Adverse effects of orthodontic treatment: A clinical perspective. Saudi Dent J. 2011;23(2):55-59.

4. Pachêco-Pereira C, Pereira JR, Dick BD, Perez A, Flores-Mir C. Factors associated with patient and parent satisfaction after orthodontic treatment: A systematic review. Am J Orthod Dentofacial Orthop. 2015;148(4):652-659. 
5. Nimeri G, Kau CH, Abou-Kheir NS, Corona R. Acceleration of tooth movement during orthodontic treatment - a frontier in orthodontics. Prog Orthod. 2013;14:42.

6. Alfawal AM, Hajeer MY, Ajaj MA, Hamadah O, Brad B. Effectiveness of minimally invasive surgical procedures in the acceleration of tooth movement: A systematic review and meta-analysis. Prog Orthod. 2016;17:33.

7. Patterson BM, Dalci O, Darendeliler MA, Papadopoulou AK. Corticotomies and orthodontic tooth movement: A systematic review. J Oral Maxillofac Surg. 2016;74(3):453-473.

8. Wilcko MT, Wilcko WM. The Wilckodontics Accelerated Osteogenic Orthodontics (AOO) technique: An overview. Orthotown. 2011;4(6):36-48.

9. Al-Naoum F, Hajeer MY, Al-Jundi A. Does alveolar corticotomy accelerate orthodontic tooth movement when retracting upper canines? A split-mouth design randomized controlled trial. J Oral Maxillofac Surg. 2014;72(10):1880-1889.

10. AlGhamdi AST. Corticotomy facilitated orthodontics: Review of a technique. Saudi Dent J. 2010;22(1):1-5.

11. Charavet $C$, Lecloux $G$, Bruwier A, et al. Localized piezoelectric alveolar decortication for orthodontic treatment in adults: A randomized controlled trial. J Dent Res. 2016;95(9):1003-1009.

12. Vercellotti T, Podesta A. Orthodontic microsurgery: A new surgically guided technique for dental movement. Int J Periodontics Restorative Dent. 2007;27(4):325-331.

13. Dibart S, Sebaoun JD, Surmenian J. Piezocision: A minimally invasive, periodontally accelerated orthodontic tooth movement procedure. Compend Contin Educ Dent. 2009;30(6):342-344,346,348-350.

14. Dibart S, Surmenian J, Sebaoun JD, Montesani L. Rapid treatment of Class II malocclusion with piezocision: Two case reports. Int J Periodontics Restorative Dent. 2010;30(5):487-493.

15. Gibreal O, Hajeer MY, Brad B. Efficacy of piezocision-based flapless corticotomy in the orthodontic correction of severely crowded lower anterior teeth: A randomized controlled trial. Eur J Orthod. 2019;41(2):188-195.

16. Alfawal AMH, Hajeer MY, Ajaj MA, Hamadah O, Brad B. Evaluation of piezocision and laser-assisted flapless corticotomy in the acceleration of canine retraction: A randomized controlled trial. Head Face Med. 2018;14(1):4.

17. Tunçer NI, Arman-Özçirpici A, Oduncuoglu BF, Göçmen JS, Kantarci A. Efficiency of piezosurgery technique in miniscrew supported en-masse retraction: A single-centre, randomized controlled trial. Eur J Orthod. 2017;39(6):586-594.

18. Proffit WR, Phillips C, Douvartzidis N. A comparison of outcomes of orthodontic and surgical-orthodontic treatment of Class II malocclusion in adults. Am J Orthod Dentofacial Orthop. 1992;101(6):556-565.

19. Rizk MZ, Mohammed H, Ismael O, Bearn DR. Effectiveness of en masse versus two-step retraction: A systematic review and metaanalysis. Prog Orthod. 2018;18:41.

20. Aksakalli S, Calik B, Kara B, Ezirganli S. Accelerated tooth movement with piezocision and its periodontal-transversal effects in patients with Class II malocclusion. Angle Orthod. 2016;86(1):59-65.

21. Al-Sibaie S, Hajeer MY. Assessment of changes following en-masse retraction with mini-implants anchorage compared to two-step retraction with conventional anchorage in patients with class II division 1 malocclusion: A randomized controlled trial. Eur J Orthod. 2014;36(3):275-283.

22. Dinçer $M, G$ ülşen $A$, Türk T. The retraction of upper incisors with the PG retraction system. Eur J Orthod. 2000;22(1):33-41.

23. Hoggan BR, Sadowsky C. The use of palatal rugae for the assessment of anteroposterior tooth movements. Am J Orthod Dentofacial Orthop. 2001;119(5):482-488.

24. Matsui S, Caputo AA, Chaconas SJ, Kiyomura H. Center of resistance of anterior arch segment. Am J Orthod Dentofacial Orthop. 2000;118(2):171-178.

25. Uribe F, Padala S, Allareddy V, Nanda R. Patients', parents', and orthodontists' perceptions of the need for and costs of additional procedures to reduce treatment time. Am J Orthod Dentofacial Orthop. 2014;145(4 Suppl):S65-S73.
26. Keser El, Dibart S. Sequential piezocision: A novel approach to accelerated orthodontic treatment. Am J Orthod Dentofacial Orthop. 2013;144(6):879-889.

27. Fischer TJ. Orthodontic treatment acceleration with corticotomyassisted exposure of palatally impacted canines. Angle Orthod. 2007;77(3):417-420.

28. Bhattacharya $P$, Bhattacharya $H$, Anjum A, et al. Assessment of corticotomy facilitated tooth movement and changes in alveolar bone thickness - a CT scan study. J Clin Diagn Res. 2014;8(10):ZC26-ZC30.

29. Sakthi SV, Vikraman B, Shobana VR, lyer SK, Krishnaswamy NR. Corticotomy-assisted retraction: An outcome assessment. Indian J Dent Res. 2014;25(6):748-754.

30. Khlef HN, Hajeer MY, Ajaj MA, Heshmeh O. En-masse retraction of upper anterior teeth in adult patients with maxillary or bimaxillary dentoalveolar protrusion: A systematic review and meta-analysis. J Contemp Dent Pract. 2019;20(1):113-127. 